\title{
Diabetes during and after pregnancy: Screen more, monitor better
}

\section{David Simmons MD}

$\infty$ See related research paper by Feig and colleagues, page 229

$\mathrm{T}$ he original diagnostic criteria for gestational diabetes were introduced as a test to predict future permanent diabetes among women in whom relative hyperglycemia developed during pregnancy. ${ }^{1}$ Since then, the impact of gestational diabetes on the offspring, in terms of fetal and obstetric outcomes ${ }^{2}$ and obesity and diabetes subsequent to birth, ${ }^{3}$ has become a major focus. In this issue of CMAJ, Feig and colleagues ${ }^{4}$ report their findings of the probability of progression from gestational diabetes to permanent diabetes. Their report is timely, allowing renewal of attention to an important condition where we could do better.

One area needing improvement is the prevention of progression to diabetes. Feig and colleagues comment on the growing body of data that clearly show that we can delay or prevent such progression. The Diabetes Prevention Program, a large randomized controlled trial of lifestyle intervention or metformin therapy for the prevention of progression to diabetes, ${ }^{5}$ included among its participants women with a history of gestational diabetes. The 55\% reduction in incidence of diabetes among these women was comparable to that achieved among the other trial participants. However, even though the cost-effectiveness ${ }^{6}$ and long-term benefit ${ }^{7}$ of such interventions have been demonstrated, adequate investment in intensive lifestyle coaching and support is not in place for these high-risk women.

The study by Feig and colleagues confirms the growing prevalence of gestational diabetes around the world. It also shows that the rate of progression to permanent diabetes appears to be speeding up. This is consistent with international data showing a pandemic of diabetes and obesity. Cheung and Byth, ${ }^{8}$ in a meta-analysis of controlled observational studies of progression from gestational diabetes to permanent diabetes, found that $10 \%-31 \%$ of women with permanent diabetes who had a history of pregnancy had previously had gestational diabetes. Halving the incidence of diabetes ${ }^{5}$ would clearly have a substantial impact.

Many women who have had gestational diabetes become pregnant again. Progression to permanent diabetes (usually type 2 diabetes) can occur in the interim. Any subsequent offspring are at risk not only of future diabetes and obesity ${ }^{3}$ but also of the teratogenic effects of exposure to hyperglycemia in utero. Type 2 diabetes in pregnancy, particularly if previously undiagnosed, is associated with poor outcomes, including an increased incidence of fetal loss, malformation and perinatal death. ${ }^{9}$ The incidence of these events is often as high

\section{Key points}

- The prevalence of gestational diabetes is increasing, and the time from occurrence to progression to permanent diabetes appears to be shortening.

- Current evidence supports intensive lifestyle intervention for women with a history of gestational diabetes, for the benefit of both the woman and any future offspring.

- Systematic approaches for detecting new diabetes among women with a history of gestational diabetes are needed, particularly among women who may become pregnant in the future.

- All pregnant women should be given information about the risks associated with gestational diabetes and offered screening so that they can make an informed choice about whether to be tested for the condition.

as or even higher than that among women with type 1 diabetes. So far, economic evaluation of interventions to prevent progression to diabetes after gestational diabetes has not included the costs of such adverse effects on the fetus and mother. The potential to protect future offspring of women with past gestational diabetes would be expected to strengthen the case for investing in primary prevention programs for these women.

Another area where we need to do better is the diagnosis of type 2 diabetes before pregnancy. Even if there were no primary prevention programs in place, there should be secondary prevention programs to detect diabetes as near to its development as possible. Such programs would allow control of hyperglycemia before a subsequent pregnancy, something clearly of benefit to any future fetus. The possibility of fetal malformation and death early in the pregnancy can also be very distressing to the mother. The recommended process to detect permanent diabetes in women who have had gestational diabetes and who might become pregnant again is an oral glucose tolerance test $6-12$ weeks post partum and every 1-2 years thereafter. ${ }^{5}$ A cost-effectiveness study of postpartum testing for diabetes described a strategy of administering the oral glucose tolerance test (not a fasting glucose or glycosylated hemoglobin $\left[\mathrm{HbA}_{\mathrm{cc}}\right]$ test) every 3 years..$^{10}$ This would be the recommended strategy for women who are not likely to become pregnant again.

David Simmons is with the Institute of Metabolic Science, Cambridge University Hospitals NHS Foundation Trust, Cambridge, United Kingdom. 
Few reports have been published regarding the uptake of such postpartum screening, follow-up and diagnosis. One report of a Canadian study involving 254 pregnancies showed substantial room for improvement in screening women with previous gestational diabetes for new diabetes. ${ }^{11}$ Indeed, given the reliance by Feig and colleagues on newly diagnosed cases of diabetes being captured in the diabetes database they used, any underscreening would imply that the true rates of progression to diabetes are even greater than those apparent from the data presented.

A third area where we need to do better is the detection of gestational diabetes in the first place. Although widely used evidence-based criteria for gestational diabetes would be helpful, the clear evidence that management of the condition is associated with improved fetal and obstetric outcomes ${ }^{2}$ would suggest that all pregnant women should be offered the opportunity to be screened for gestational diabetes. Reasons why the test is warranted can now include the quantitative estimate of future risk of permanent diabetes should gestational diabetes be detected, as shown by Feig and colleagues, and the evidence that intensive lifestyle management can reduce this risk. These reasons, as well as the evidence that harm to both mother and fetus can be reduced through the management of gestational diabetes, may well mean that most pregnant women will opt for screening, given the choice.

Competing interests: None declared.

Acknowledgement: I thank the Cambridge Comprehensive Biomedical Research Centre of the National Institute for Health Research for its financial support.

\section{REFERENCES}

1. O'Sullivan JB. Diabetes mellitus after GDM. Diabetes 1991;40:131-5.

2. Crowther CA, Hiller JE, Moss JR, et al. Effect of treatment of gestational diabetes mellitus on pregnancy outcomes. N Engl J Med 2005;352:2477-86.

3. Dabelea D. The predisposition to obesity and diabetes in offspring of diabetic mothers. Diabetes Care 2007;30(Suppl 2):S169-74.

4. Feig DS, Zinman B, Wang X, et al. Risk of development of diabetes mellitus after diagnosis of gestational diabetes. CMAJ 2008;179(3):229-34.

5. Ratner RE. Prevention of type 2 diabetes in women with previous gestational diabetes. Diabetes Care 2007;30(Suppl 2):S242-5.

6. Herman WH, Hoerger TJ, Brandle M, et al.; Diabetes Prevention Program Research Group. The cost-effectiveness of lifestyle modification or metformin in preventing type 2 diabetes in adults with impaired glucose tolerance. Ann Intern Med 2005;142:381-3.

7. Lindström J, Ilanne-Parikka P, Peltonen M, et al.; Finnish Diabetes Prevention Study Group. Sustained reduction in the incidence of type 2 diabetes by lifestyle intervention: follow-up of the Finnish Diabetes Prevention Study. Lancet 2006; 368:1673-9

8. Cheung NW, Byth K. The population health significance of gestational diabetes. Diabetes Care 2003;26:2005-9.

9. Feig DS, Palda VA. Type 2 diabetes in pregnancy: a growing concern. Lancet 2002;359:1690-2.

10. Kim C, Herman WH, Vijan S. Efficacy and cost of postpartum screening strategies for diabetes among women with histories of gestational diabetes mellitus. Diabetes Care 2007;30:1102-6.

11. Clark HD, van Walraven C, Code C, et al. Did publication of a clinical practice guideline recommendation to screen for type 2 diabetes in women with gestational diabetes change practice? Diabetes Care 2003;26:265-8.

Correspondence to: Dr. David Simmons, Wolfson Diabetes and Endocrinology Clinic, Institute of Metabolic Science, Box 281, Addenbrooke's Hospital, Cambridge University Hospitals NHS Foundation Trust, Cambridge CB2 OQQ UK; fax 441223217 080; david.simmons@addenbrookes.nhs.uk

\section{Holiday Reading}

\section{Call for submissions}

Do you have something profound or profoundly entertaining to say? CMAJ may be just the place to publish. In December 2008, we will present a special Holiday Reading section - a deviation from our usual Holiday Review fare. The section will feature essays, creative non-fiction, short fiction and narrative medicine articles. Your missive can be ethical or satirical, personal or academic, plainly frivolous or gratuitously entertaining; the common thread is medicine in all its permutations.

Articles should be no longer than 1200 words; photographs and illustrations are welcome. Send your submissions for consideration via our online manuscript system (http://mc.manuscript central.com/cmaj). Please mention in your cover letter that your submission is intended for this year's Holiday Reading issue.

The deadline for submissions is Oct. 7, 2008.

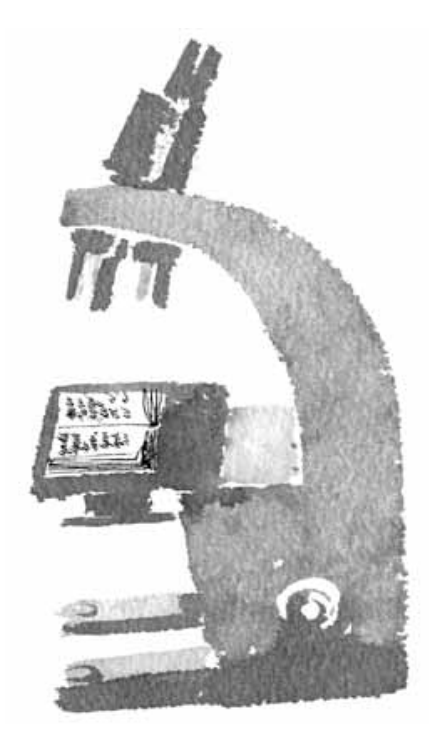

